\title{
A Discussion on Innovation of Engineering Project Management Methods under the Background of Big Data
}

\author{
Yuhai Miao \\ City Institute, Dalian University of Technology, Dalian City, Liaoning Province, 116600, China
}

Keywords: big data; project management; interactivity; management innovation

\begin{abstract}
With the progress and development of the times, and the advent of the era of knowledge, especially the rapid development of big data, all industries face complex and diverse data. How to mine, manage, analyze and use the data is a problem that every manager will confront when they come into contact with big data. Based on the author's learning and practical experience, this paper first analyzes the interactivity between big data mining and engineering project management and then compares traditional project management innovation with project management innovation under the background of big data. Finally, the article proposes a project management innovation model based on big data.
\end{abstract}

\section{Introduction}

With the advent of the age of information and knowledge, especially the booming development of big data, China's engineering project management has been severely challenged. Previous management methods have struggled to adapt to the requirements of the time. A large amount of information and data is the foundation of engineering project construction. From the perspective of scientific and technological management, the information and data is the foundation of engineering project construction and these information resources has become an important bottleneck of engineering management at this stage. Engineering project management is a system management method that targets an engineering project. The overall goal is achieved through dynamic management of the entire process of the project.

\section{Interactivity between Big Data Mining and Engineering Project Management}

\subsection{Development trend of engineering project management under the background of big data}

With the rapid development of social economy, advanced scientific and technological management has become one of the ways to obtain competitive advantage in all walks of life, and it is also an important task for engineering project management. Relying on computer technology, and taking large information flow and resource flow as management object, scientific and technological management provides a network information platform for gathering, screening, archiving and transmission of tedious information resources to realize the routing, informationalized and automatic management of technology activities. Based on these characteristics of scientific and technological management, China's engineering project management also presents trends in diversified, dynamic and informationalized management with data. On one hand, in the traditional industry, the engineering industry is an industry with the largest amount of data and project scale. The characteristics of multiple projects, wide coverage, time-consuming process and diverse influencing factors have determined that the information management of the project is diverse. The diversity of information data is reflected in all aspects of project management. For example, there are many sources of information in early decision-making. Manpower, material resources and financial management are all based on various information resources. On the other hand, engineering project management adopts a full-cycle management model with long time, and various information flows are continuously distributed in dynamic time stream. Therefore, the informationalized management of engineering projects is the trend of the time. 


\subsection{Big data mining provides a new path for the optimization of engineering project management}

The emergence of big data will create new development opportunities for scientific and technological information management of engineering projects and create optimization paths for efficiency management, quality management and risk management of engineering projects. Big data mining helps to improve the efficiency of engineering project management. Due to the systematic nature and complexity of the project, the inefficiency of engineering project management is widespread. Big data mining can improve data management efficiency with advanced technology. The author takes performance appraisal of engineering project management as an example. Performance appraisal often has many problems, such as too many indicators and excessive evaluation costs. Big data mining brings new methods to solve these problems. The introduction of big data mining technology in engineering project management can find the performance indicators that are most in line with the project requirements: the key performance indicators, which will reduce the workload of engineering project management and improve the performance management efficiency. Big data mining brings new ideas for comprehensive risk management of engineering project management. In the engineering industry, various risks are hidden in large and complex data, which brings hidden dangers to the project and even to the long-term development of the company. In big data management, the data warehouse not only collects existing and historical data in a timely manner, but also processes and converts isolated data in a preliminary manner to form a unified data set that is related to each other. This will provide transparent information platform for each data user in the project and reduce the risk of false information and communication barriers in information flow.

\section{Comparison between Traditional Project Management Innovation with Project Management Innovation under the Background of Big Data}

\subsection{Differences between innovation environment and conditions}

The basic background of traditional project management innovation is the "pond" which means a limited ecology. This implies that innovation is built around the resources that may be possessed by a few project-based organizations, such as organizational knowledge and expert wisdom. The limited resources impose restrictions on innovation means and methods. The basic background of project management innovation under the background of big data is "ocean" which means unlimited resources to some extent. Project management innovation under the background of big data not only depends on the project-based organizations, but also makes use of resources from a more extensive organizational ecology to create more favorable conditions for innovation.

\subsection{Differences between driving factors, and innovation ways and paths}

Traditional project management innovation is a problem-driven method to find a top-down innovative solution with Delphi method, brainstorming method, decision tree method and other qualitative or quantitative methods and resources provided by project-organized organization leaders and management experts in the "pond". In the context of big data, innovation may not only be driven by problems, but may also be based on data. In more cases, it is a combination of the two. That is raising questions and then using data to identify problems. Taking into account the sharing nature of data, project management innovation can be achieved through more extensive participation in the context of big data. The common cloud computing and data analysis currently can also be used for traditional project management innovation, but in the context of big data, the breadth and depth of application of this issue is completely different.

\subsection{Difference between innovation results and key to success}

In the traditional project management innovation, limited by innovation background, conditions and means, the possible innovative solutions are limited and the key to the success of the final innovation solution lies in the application of expert knowledge within the constraints of resources. 
In the context of big data, there are more possibilities for innovative solutions and the decision of the final innovation plan mainly depends on the results of data analysis and the interpretation of the results of the project organization. The key to the success of the innovation program in practice lies in the availability of data and accuracy of data analysis results and interpretation.

\section{Project Management Innovation Model Based on Big Data}

\subsection{Definition of data acquisition and innovation issues}

At the beginning of the project, the project-based organization must first determine whether to carry out project management innovation. The key issue involved in this decision is data acquisition. With the help of BIM technology, the main technical data of the project is presented in two or three dimensions. With the help of data conversion technology, other existing forms of data can be converted into electronic information. In virtue of various information retrieval techniques, relevant data on the media can be collected and used with search engines. Based on the data, project-based organizations assess whether they want to conduct innovation and whether they can conduct innovation. Once a positive answer is made, data management should be used to determine the project management innovation issues based on project-based organization management and expert knowledge. The definition of a problem usually consists of two stages: First, the range or area in which the innovation needs to be identified is roughly determined; second, the preliminary qualitative analysis of the data is used to clearly define innovation issues.

\subsection{Data processing, analysis and innovation plan decision-making}

The decision-making of the project management innovation plan is the main task ate the stage. The formation and decision-making of the innovation plan depends on the data processing and analysis. The various types of data acquired by project-based organizations need further processing. First, a large amount of semi-structured data and unstructured data must be converted into structured data that can be used for analysis through data integration and data extraction to form a data platform for project management innovation. Then, professional analysts apply cloud computing, data mining techniques, statistical analysis and other analysis techniques to find the relevance model between various types of data within the scope of project management innovation. They need to identify key factors that may affect the success or failure of innovation through data analysis to find the core issues in project management innovation. Project management innovation generally involves a large number of problems. The results of data processing are different due to the availability of data, the professional capabilities of data personnel, the data processing methods and the interpretation of the analysis results, which may affect the scientific nature and rationality of project management innovation plans. By sharing information on the data platform, project-based organizations can obtain project management innovation plans at different levels and in different dimensions. First, leaders or experts in project-based organizations form top-down project management innovation plans based on data analysis results. Second, staff in project-based organizations form a bottom-up project management innovation plan according to the results of data analysis. Third, persons out of project-based organizations can use the online channel to collect plans formed by data sharing platforms to ultimately form a project management innovation plan collection. According to the results of data processing and analysis, the alternative project innovation management plans are re-validated, including the rationality and scientific basis for the formation of the plan, the probability of successful implementation of the project and the possible outcomes, so as to select the optimal solution.

\subsection{Dynamic data and implementation of innovation plans}

Innovation plans are implemented during the project life cycle. As the project progresses, on one hand, data on project implementation is accumulated. On the other hand, data on implementation performance of innovation plans is also accumulated. The two types of data are collected and processed to become a part of the data sharing platform and provide a basis for the performance 
evaluation of project innovation plans. At the same time, the analysis results of dynamic data are helpful for the dynamic optimization of project innovation plans. This ensures that the solution is not a static process, but is in the process of continuous improvement as the project progresses.

\subsection{A new round of data collection and analysis process, and improvement of innovation plans}

The project management innovation plans based on big data has always undergone the test of data analysis results, and it has been applied to other similar projects with the help of data collection and analysis. Therefore, it may avoid the difficulties brought by the referential innovation. Through the collection and further analysis of the relevant data of the new project, the original project management innovation plan can be corrected in an appropriate manner, so as to achieve improvements in the project management innovation plans to some extent.

\section{Conclusion}

Big data mining has been applied in various fields of social economy. This article discussed its application in the field of engineering management. The innovation lies in the fact that the key point based on engineering management is to establish a big data mining project team and conduct application studies of model design of data mining project team with a construction progress schedule. The field of engineering management is very wide and the key point is different in different projects. The author will strengthen the applied research in future.

\section{References}

[1] Xi Yi. A Research on Management Method of Technological Innovation in Big Data Environment [J]. Science \& Technology Industry Parks, 2017, (16): 207-208.

[2] Qin Lina. An Analysis of Technological Innovation Management Method Based on Big Data Environment [J]. Telecommunications, 2017, (07): 71-72.

[3] Jiang Feng. A Research on Technological Innovation Management Method in Big Data Environment [J]. China New Telecommunications, 2016, (01):27.

[4] Dong Jiawei. An Exploration of Improvement of Project Management Method in Big Data Environment [J]. Project Management Technology, 2015, (06):103-106.

[5] Gao Xiaoyun. A Discussion on Technological Innovation Management Method Based on Big Data Environment [J]. China Management Informatization, 2015, (01):212-213.

[6] Zhu Donghua, Zhang Yi, Wand Xuefeng, LI Bing, Huang Ying, Ma Jing, Xu Xingrong, Yang Chao, Zhu Fujin. A Research on Management Method of Technological Innovation in Big Data Environment [J]. Science of Science and Management of S. \& T., 2013, (04) :172-180. 